\title{
Exploiting the Potential of Moringa oleifera Oil/Polyvinyl Chloride Polymeric Bionanocomposite Film Enriched with Silver Nanoparticles for Antimicrobial Activity
}

\author{
Musarat Amina $\mathbb{D}^{1},{ }^{1}$ Nawal M. Al Musayeib $\mathbb{D},{ }^{1}$ Nawal A. Alarfaj, ${ }^{2}$ Maha F. El-Tohamy $\mathbb{D}^{2}{ }^{2}$ \\ Hisham E. Orabi, ${ }^{3}$ Sarah I. Bukhari, ${ }^{4}$ and Amany Z. Mahmoud ${ }^{4}$ \\ ${ }^{1}$ Department of Pharmacognosy, Pharmacy College, King Saud University, Riyadh 11451, Saudi Arabia \\ ${ }^{2}$ Department of Chemistry, College of Science, King Saud University, P.O. Box 22452, Riyadh 11495, Saudi Arabia \\ ${ }^{3}$ Deanship of Scientific Research, Umm Al-Qura University, Makkah, Saudi Arabia \\ ${ }^{4}$ Department of Pharmaceutics, College of Pharmacy, King Saud University, Riyadh 11451, Saudi Arabia
}

Correspondence should be addressed to Maha F. El-Tohamy; star2000star@gmail.com

Received 21 January 2019; Revised 18 April 2019; Accepted 5 May 2019; Published 17 June 2019

Academic Editor: Cornelia Vasile

Copyright ( 2019 Musarat Amina et al. This is an open access article distributed under the Creative Commons Attribution License, which permits unrestricted use, distribution, and reproduction in any medium, provided the original work is properly cited.

\begin{abstract}
The present study focused on the prospect of fabricating a polymeric naturally extracted Moringa oleifera oil bionanocomposite film enriched with silver nanoparticles for antimicrobial activity. In this study, a standard concentration of Moringa oleifera oil (5-10 wt\%) was used to fabricate a polymeric bionanocomposite film using polyvinyl chloride (PVC) enriched with silver nanoparticles. The active constituents of the extracted Moringa oleifera oil were verified using gas chromatography-mass spectrometry. Spectroscopic and microscopic techniques, including scanning electron microscopy, X-ray diffraction, and energydispersive X-ray analysis, were employed to characterize and study the surface morphology of the fabricated bionanocomposite film. The antimicrobial activity of the fabricated bionanocomposite film was investigated using different strains of bacteria and fungus. The results revealed well-oriented and excellently dispersed silver nanoparticles in the PVC-Moringa oleifera oil matrix. The bionanocomposite was able to inhibit the growth of Staphylococcus aureus, Escherichia coli, Klebsiella pneumoniae, Salmonella typhi, Pseudomonas aeruginosa, Shigella flexneri, and Candida albicans. The combination of nanoparticles with polymers is opening new routes for engineering fixable composites, which showed antimicrobial properties.
\end{abstract}

\section{Introduction}

Enhancing the antimicrobial effects of different oils is very crucial for treating resistant infectious pathogenic microbes. Several plants with antimicrobial activities are considered a potent source of unique antimicrobial functions. Native to India, Moringa oleifera is widely used as a functional food and medicinal plant that has high nutritional value and diverse pharmacological activities due to the essential phytochemicals existent in its leaves, pods, and seeds [1]. The seeds of Moringa have attracted scientific interest for their macronutrient composition, for their potential for oil production, and for being a significant source of protein. Several studies have concluded that the phytochemical compounds and secondary metabolites in its seeds have an excellent antioxidant activity, and they have been used as nutraceutical molecules. Seeds contain a range of $4.58-4.95 \mathrm{~g} / 100 \mathrm{~g}$ of total phenolic compounds, where gallic acid is predominating, followed by ellagic and caffeic acids. Smaller amounts of several other phenolic acids, such as p-coumaric, vanillic, ferulic, and cinnamic acids, have also been identified. Additionally, the seeds of Moringa contain a significant amount of oil (up to 40\%) with a distinguished resistance to oxidative degradation after refining [2]. Commercially, Moringa oil is known as "Behen oil," due to the presence of appreciable amounts of behenic acid along with palmitic and stearic acids as well as oleic acid (more than 70\%) [3]. Different sterols such as stigmasterol, campesterol, $\beta$-sitosterol, and $\delta^{5}$-avenasterol and traces of 24-methylenecholesterol, stigmastanol, and campestanol as well as 24-isoavenasterol have been found [4]. The 
pharmacological studies of Moringa oil have claimed various biological activities including antibacterial, antifungal, antioxidant, antifertility, and anticancer effects [5]. The oil has also been reportedly used in the treatment of arthritis rheumatism and hypertension [6].

Nowadays, nanoencapsulation (imbedding metal nanoparticles within polymer matrices) is a novel frontline technology in the field of nanoscience which, depending on the application, can be tailored to improve a number of desired properties. Recently, there has been enormous interest in polymer nanocomposites because of their low cost and high-performance potential for an unlimited spectrum of applications in automotive, aerospace, building construction, military, packaging, pharmaceutical, medical devices, and other industries. Nanoparticles possess a viable alternative feature to antibiotics and have a high potential activity against drug resistant bacteria [7]. Due to its low cytotoxicity [8], silver nanoparticles (AgNPs) have been used as an antimicrobial and antiseptic. They have also been used against various gram-positive and gram-negative bacteria [9-11]. The literature survey has revealed very few reports which studied Moringa oleifera oil in polymeric mixtures. In 2018, Finzi-Quintao et al. reported a comparative study of Moringa oleifera oil in mixtures with commercial polymers [12]. Furthermore, Finzi-Quintao et al. suggested another study in 2019 concerned with the biodegradation of Moringa oleifera's polymer blends [13]. In 2016, Abd-Rabou et al. addressed and explored the potential of Moringa oleifera seed oil as an impact compound to promote the mechanism of mitochondrial apoptosis of cancer cell death [14].

PVC is the third widely important plastic polymer after polyethylene and polypropylene. It has high mechanical and hardness properties [15]. Furthermore, marvelous applications have been reported for PVC in various fields such as biomaterials [16], polymers in sensors [17] and biosensors [18], and medical and healthcare [19] as well as in cytotoxicity and cytokine release [20]. Considering the unique benefits of Moringa oleifera oil incorporated with PVC and decorated with silver nanoparticles as a bionanocomposite, the present study is aimed at using PVC as a supporting material for the fabrication of a polymeric Moringa oleifera oil bionanocomposite enriched with silver nanoparticles (AgNPs). The prepared bionanocomposite was screened for antimicrobial activity.

\section{Materials and Methods}

2.1. Botanical Materials. Moringa oleifera materials were collected from Jazan, Saudi Arabia, where trees were grown in local farms. Following collection, seeds were separated from the pods (fruits) and packed in polyethylene plastic bags. Seeds were sun dried to reduce moisture content. The dried seeds were ground into fine powder with an electric grinder for solvent extraction. The sample was stored in a safe, cool, dry place until further use.

2.2. Chemicals and Reagents. Pure grade high molecular weight polyvinyl chloride (PVC), silver nitrate $\left(\mathrm{AgNO}_{3}\right.$, 99.89\%), tetrahydrofuran (THF), N,N-dimethylformamide
(DMF, 99.0\%), methanol (LR, $\geq 99.0 \%$ ), and chloroform (anhydrous, $\geq 99.0 \%$ ) were acquired from Sigma-Aldrich (Hamburg, Germany).

2.3. Microorganisms. Antimicrobial activity experiments were performed using Staphylococcus aureus (ATCC 25923), Escherichia coli (ATCC 25922), Klebsiella pneumoniae (ATCC 27736), Salmonella typhi (ATCC 27736), Pseudomonas aeruginosa (ATCC 25566), Shigella flexneri (ATCC 11060), and Candida albicans (ATCC 10231) stains. The bacterial strains were obtained from the microbiology laboratory of King Khalid Hospital, Saudi Arabia.

2.4. Oil Extraction. For solvent extraction, $200 \mathrm{~g}$ of ground Moringa oleifera seeds were placed in a thimble paper and inserted at the center of the extractor tube. The extractor tube was transferred to the extraction chamber in the Soxhlet apparatus. Approximately $500 \mathrm{~mL}$ of the organic extraction solvent mixture (ratio of chloroform:methanol, 1:1) was added into the solvent flask and placed on the heating mantle. The cold-water supply was opened to the condenser to ensure continuous recycling of the solvent. The extraction chamber was arranged in such a way that when the extraction solvent surrounding the sample thimble exceeds a certain level, it flows and trickles back down into the boiling round bottom flask. This cycle was allowed to repeat until complete oil extraction from the solid sample was achieved. Then, the flask containing oil was removed from the extractor tube, filtered through filter papers, and the organic solvent was removed from the collected solution using a rotary evaporator under reduced pressure. The residual solvent was removed using a drying oven at $60^{\circ} \mathrm{C}$ for $1 \mathrm{~h}$ and flushed with nitrogen (99\%) to acquire the Moringa seed oil. The extracted oil was then weighed and stored in a plastic container for further analysis.

2.5. Gas Chromatography/Mass Spectrometry Analysis of Moringa Seed Oil. The analysis of the fatty acid composition of Moringa seed oil extracted by a Soxhlet apparatus was obtained using GC-MS after the derivatization of the fatty acids into fatty acid methyl esters (FAME). FAME separation and identification were carried out using the PerkinElmer Clarus 600 gas chromatograph aligned to a mass spectrometer (TurboMass). Approximately, $1 \mu \mathrm{L}$ of the derivatized sample was injected into a $30 \mathrm{~m}$ long Elite-5MS GC column with $0.25 \mu \mathrm{m}$ film thickness and $0.25 \mathrm{~mm}$ internal diameter. The oven temperature of the GC-MS system was programmed as follows: the initial temperature was $40^{\circ} \mathrm{C}$, increasing this to $100^{\circ} \mathrm{C}$ at a rate of $5^{\circ} \mathrm{C} / \mathrm{min}$, hold for 2 minutes, increasing from $100^{\circ} \mathrm{C}$ to $200^{\circ} \mathrm{C}$ at the transfer line heater at a rate of $5^{\circ} \mathrm{C} / \mathrm{min}$, hold for $5 \mathrm{~min}$, and then using a final temperature of $300^{\circ} \mathrm{C}$ for another $5 \mathrm{~min}$. The injector temperature and the inlet temperature of the MSD (mass selective detector) solvent (delay 3.5 minutes) were maintained at $220^{\circ} \mathrm{C}$ and $300^{\circ} \mathrm{C}$, respectively. The mobile phase used was helium at a volumetric flow rate of $1.0 \mathrm{~mL} / \mathrm{min}$. The detection of the mass spectrum was determined by scanning at 40 to 600 a.m.u. in an electron ionization mode. Finally, the identification of unknown compounds was 
obtained by comparing the spectra available from the National Institute of Standard and Technology library(NIST 2005) and the Wiley Library 2006 (ver. 2.1). The total time needed for analysis of a single sample was $30 \mathrm{~min}$. The calculated Retention Index (RI) was determined by running the standard solution of C-7 to C-30 saturated alkanes standard from Supelco with the same method as the sample. The concentration of alkanes was $1000 \mu \mathrm{g} / \mathrm{mL}$. The RI values were calculated using the AMDIS32 software.

2.6. Identification of Constituents of Moringa Seed Oil by GC-MS. The components of Moringa oil were identified on the basis of GC retention time, their matching with the Wiley Library 2006, and comparing the fragmentation pattern of their mass spectra with those already mentioned in the literature $[21,22]$. The identified constituents were recognized as fatty acid, sterols, alkanes, and alcohol compounds.

2.7. Fabrication of Plain and Moringa oleifera Oil/PVC-Ag Bionanocomposite. A simple process to fabricate an ultrafine PVC polymer and Moringa oleifera oil/PVC-Ag bionanocomposite film was employed. Briefly, to prepare $10 \%$ of a PVC solution, $10 \mathrm{~g}$ of high molecular weight PVC was dissolved in THF:DMF $(1: 1 w / w)$ under magnetic stirring overnight at room temperature. A homogenous Moringa oleifera oil/PVC composite was obtained by adding 5-10 wt $\%$ of Moringa oleifera oil to the PVC polymer solution with continuous stirring for $3 \mathrm{~h}$ at room temperature until the formation of a homogenous and uniformly distributed Moringa oleifera oil/PVC composite. A Moringa oleifera oil/PVC-AgNP bionanocomposite membrane was prepared by mixing 5-10 wt \% of Moringa oleifera oil and $3 \mathrm{wt} \%$ of silver nitrate with the polymeric solution under vigorous stirring for $3 \mathrm{~h}$ at room temperature. The polymeric Moringa oleifera oil/PVC-AgNP bionanocomposite film was formed, and the collected solution was stored for further studies.

2.8. Characterization. Spectroscopic and microscopic investigations of the fabricated Moringa oleifera oil/PVC-AgNP bionanocomposite were performed to ensure the morphological features. The XRD patterns of PVC, Moringa oleifera oil, and the Moringa oleifera oil/PVC-AgNP bionanocomposite were studied using an X-ray diffractometer (D/MAX 2500, Rigaku Corporation, Tokyo, Japan), operated by adjusting the voltage and current at $30 \mathrm{kV}$ and $40 \mathrm{~mA}$ over Bragg angles between 10 and 70 degrees. Furthermore, the surface morphology of the prepared bionanocomposite was investigated at different magnifications using a scanning electron microscope (SEM) (JSM-7610F; JEOL, USA). Also, the chemical composition of the Moringa oleifera oil/PVC-AgNP bionanocomposite was tested using an energy-dispersive X-ray spectrometer (EDX) equipped with a SEM apparatus. The size distribution was assessed by ImageJ software (a scriptable Java app for scientific image processing).

2.9. Thermal Stability of Bionanocomposite Film. Thermogravimetric analysis was used to study the thermal stability of the Moringa oleifera oil and the AgNP bionanocomposite film. The experiment was conducted under the continuous argon flow of a Shimadzu thermogravimetric analyzer
(TGA-502 model) with a scanning range from 5 to $500^{\circ} \mathrm{C}$ and a heating rate of $10^{\circ} \mathrm{C} \mathrm{min}^{-1}$.

\subsection{Antimicrobial Activity}

2.10.1. Determination of Antibacterial Activity of Moringa oleifera Oil and Moringa oleifera Oil/PVC-AgNPs. The disc diffusion method was used to investigate the antibacterial activity [23]. It was performed using the Mueller-Hinton agar $18 \mathrm{~h}$ culture plates at $37^{\circ} \mathrm{C}$. The bacterial suspension was adjusted to a bacterial cell density of $1.0 \times 10^{8} \mathrm{UFC} / \mathrm{mL}$ with a sterile saline solution. A sterile swab immersed in each bacterial suspension was spread over the plates in order to get a uniform microbial growth on both test plates and control. $10 \mu \mathrm{L}$ of Moringa oleifera oil and $10 \mu \mathrm{L}$ of the Moringa oleifera oil/PVC-AgNP bionanocomposite were applied on the sterile disc. All were placed on the surface of $20 \mathrm{~mL}$ plates inoculated with microorganisms. Then, plates were incubated for 15 minutes at room temperature followed by $24 \mathrm{~h}$ of incubation at $37^{\circ} \mathrm{C}$. The inhibition zones were measured in millimeters [24]. A standard disc containing ciprofloxacin (5 $\mu \mathrm{g} /$ disc, MASTDISCS ${ }^{\mathrm{TM}}$, Mast Diagnostics Ltd.) was used as a reference control for bacterial inhibition, and fluconazole (5 $\mu \mathrm{g} /$ disc, MASTDISCS ${ }^{\mathrm{TM}}$, Mast Diagnostics Ltd.) was considered the positive control of fungal inhibition. All experiments were carried out in triplicates, and the mean inhibition diameter was calculated. The effect was classified as either "sensitive" or "resistant" with a cutoff value equal to $8 \mathrm{~mm}$.

2.10.2. Determination of Minimum Inhibitory Concentration "MIC." Moringa oleifera oil and the Moringa oleifera oil/PVC-AgNP bionanocomposite with a large inhibition diameter were tested for the antimicrobial potential against each microorganism. Minimum inhibitory concentration (MIC) was determined by a broth microdilution protocol using the Mueller-Hinton broth in a 96-well microtiter tray. Tween 80 (Sigma-Aldrich) was added to the broth to enhance the solubility of Moringa oleifera oil and the Moringa oleifera oil/PVC-AgNP bionanocomposite. A range of three dilutions of the Moringa oleifera oil/PVC-AgNP bionanocomposite from $50 \%$ to $25 \%$ to $12.5 \%(v / v)$ were used [24]. Briefly, each well was inoculated with one of the serial dilutions of Moringa oleifera oil and the Moringa oleifera oil/PVC-AgNP bionanocomposite plus $10 \mu \mathrm{L}$ of bacterial inoculum. The Mueller-Hinton broth and Moringa oleifera oil and the Moringa oleifera oil/PVC-AgNP bionanocomposite were used as a negative control. Meanwhile, the MuellerHinton broth with the microorganism inocula were used as a positive control and reference base to study the effect of Moringa oleifera oil and the Moringa oleifera oil/PVC-AgNP bionanocomposite on the tested microorganisms. After $24 \mathrm{~h}$ of incubation at $37^{\circ} \mathrm{C}$ under agitation, MIC was determined [25].

\section{Results and Discussion}

3.1. Chemical Constituents of Moringa Seed Oil by GC-MS. The Soxhlet solvent extraction of Moringa seeds resulted in the isolation of a pale-colored oil with an excellent yield of 
TABLE 1: Composition of the essential oil of the seed of M. oleifera.

\begin{tabular}{|c|c|c|c|c|c|}
\hline Peak\# & Compound name & Retention time & Area & Area\% & Height \\
\hline 1 & Methyl myristate (C14:0) & 6.790 & 1552 & 0.1059 & 616 \\
\hline 2 & Methyl palmitate (C16:0) & 10.526 & 88250 & 6.0228 & 27004 \\
\hline 3 & Methyl palmitoleate (C16:0) & 11.164 & 18316 & 1.2500 & 5448 \\
\hline 4 & Methyl heptadecanoate $(\mathrm{C} 17: 0)$ & 12.842 & 1071 & 0.0731 & 333 \\
\hline 5 & Methyl stearate $(\mathrm{C} 18: 0)$ & 15.411 & 88668 & 6.0514 & 21909 \\
\hline 6 & Methyl oleate (C18:1) & 16.076 & 1049588 & 71.6312 & 204195 \\
\hline 7 & Methyl linoleate (C18:2) & 17.279 & 7821 & 0.5337 & 1987 \\
\hline 8 & Methyl linolenate (C18:3) & 19.114 & 1745 & 0.1191 & 404 \\
\hline 9 & Methyl arachidate (C20:0) & 20.928 & 60042 & 4.0977 & 13806 \\
\hline 10 & Methyl 11-eicosenoate (C20:1) & 21.538 & 32653 & 2.2285 & 7647 \\
\hline 11 & Methyl behenate (C22:0) & 26.642 & 94216 & 6.4299 & 20168 \\
\hline 12 & Methyl erucate (C22:1) & 27.264 & 1680 & 0.1146 & 379 \\
\hline 13 & Methyl tricosanoate (C23:0) & 29.456 & 1069 & 0.0729 & 243 \\
\hline 14 & Methyl docosapentaenoate (C22:5) & 32.439 & 18595 & 1.2690 & 3384 \\
\hline Total & & & 1465267 & 100.0 & 307521 \\
\hline
\end{tabular}

$78.2 \% v / w$ based on the fresh weight. The phytochemical components of Moringa oil were analyzed using GC-MS polar and nonpolar stationary columns, which led to the identification of 14 different components representing $98.2 \%$ of the total oil composition. The identified components with their linear retention indices (LRI) and relative content in the oil are listed in Table 1.

GC chromatograph (Figure 1) of the oil showed the presence of various saturated and unsaturated fatty acids. The extraordinary degree of the oil unsaturation $(75.2 \%)$ is due to the elevated percentage of oleic acid (71.6\%) as the main unsaturated fatty acid. Other prominent fatty acids detected were palmitic acid (6.2\%), stearic acid (7.2\%), behenic acid (7.4\%), and arachidic acid (5.2\%), with small traces of linoleic, linolenic, palmitoleic, heptadecanoic, and eicosanoic acids (Table 1). The unrefined oil on electronic nose analysis showed a similar flavor to peanut oil.

3.2. Characterization of Moringa oleifera Oil/PVC-AgNPs. In the present study, gradual concentrations of Moringa oleifera oil (5-10\%) were added to optimize the suitable concentration for bionanocomposite fabrication. Initially, 5\% Moringa oleifera oil was used, but this percentage could not provide well-characterized bionanocomposites. Thus, the percentage of the added Moringa oleifera oil was gradually increased. $10 \mathrm{wt} \%$ of Moringa oleifera oil was found to be the optimal concentration to obtain the Moringa oleifera oil/PVC polymeric solution. Scheme 1, represents the formation of the Moringa oleifera oil/PVC-silver nanoparticle bionanocomposite. SEM micrographs of the plain and fabricated bionanocomposites were investigated at different magnifications. The surface morphology of $100 \mathrm{~nm}$ and $10 \mu \mathrm{m}$ plain PVC at 50000x and $800 x$ magnifications showed a smooth face with less diameter distribution (Figures 2(a) and 2(d)). Furthermore, the pictorial depiction of plain Moringa oleifera oil at 50000x magnification showed a homogenous distribution of rounded oil droplets, and at $800 \mathrm{x}$ it showed irregular and coagulant masses with tiny pores around the edges (Figures 2(b) and 2(e)). In addition, Figures 2(c) and 2(f) showed the SEM images of the fabricated Moringa oleifera oil/PVC-AgNP bionanocomposite at the same previous magnifications revealing the spherical appearance of AgNPs with particle sizes ranging between 35 and $50 \mathrm{~nm}$.

The particle size distribution of the polymer solution of PVC containing $10 \mathrm{wt} \%$ of Moringa oil was studied. The particle size distribution was determined in a diameter range of $30 \mathrm{~nm}( \pm 10 \mathrm{~nm})$ (Figures 3(a) and 3(c)). Also, the formation of the bionanocomposite of the Moringa oleifera oil/PVCAgNPs showed a homogenous distribution, and the particle diameter was altered in the range of $40 \mathrm{~nm}$ (Figures 3(b) and $3(\mathrm{~d}))$. The surface of the fabricated bionanocomposite was found to be soft, which can be explained by the appearance of AgNPs, and revealed the successful use of Moringa oleifera oil with PVC for the fabrication of the suggested bionanocomposite.

$\mathrm{X}$-ray diffraction (XRD) with $\mathrm{Cu} \mathrm{k} \alpha$ radiation $(\lambda=1.540 \mathrm{~A})$ over Bragg angles in a range from 10 to 70 degrees was used to confirm the dispersion of Moringa oleifera oil and AgNPs in the PVC polymeric solution. The applied current and voltage were kept at $50 \mathrm{~mA}$ and $30 \mathrm{kV}$, respectively. The XRD pattern of the plain PVC showed no distinguished peak spectrum (Figure 4(a)) due to the amorphous nature of the polymer as previously reported by [26]. On the other hand, the oil displayed a high-intensity broad peak near 20 degrees (Figure 4(b)). This could be attributed to the dispersion of Moringa oil in the PVC matrix causing a significant change in peak intensity. Meanwhile, in the XRD of the Moringa oleifera oil/PVC-AgNP bionanocomposite, the presence of distinct peaks at $38.18^{\circ}, 44.25^{\circ}$, and $64.74^{\circ}$ revealed Bragg's reflection from Ag (111), Ag (200), and Ag (220) (Figure 4(c)). Thus, the XRD spectra clearly indicated the presence of AgNPs in the fabricated bionanocomposite and were in consistent agreement with the previously reported results of [27]. 


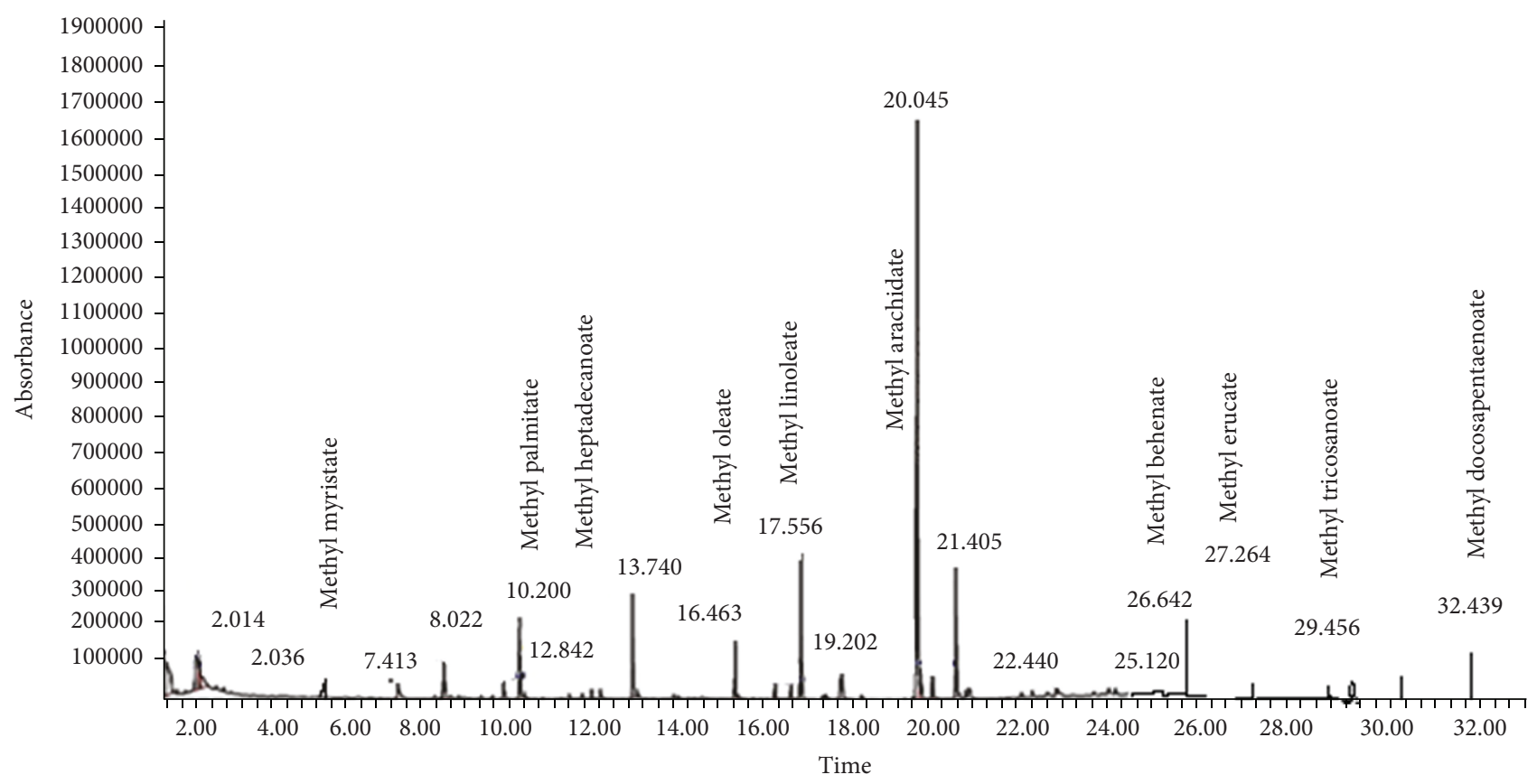

Figure 1: GC chromatogram of Moringa oleifera seed oil.
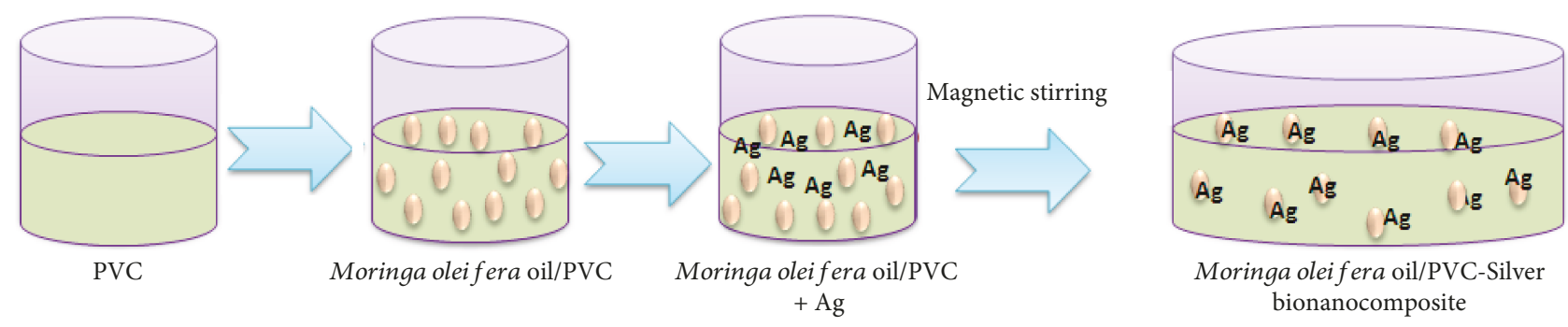

Scheme 1: Schematic illustration of Moringa oleifera oil/PVC-silver nanoparticle bionanocomposite fabrication.

Energy-dispersive X-ray (EDX) analysis of the plain PVC and Moringa oleifera oil/PVC-AgNP bionanocomposite was investigated using an EDX equipped with SEM.

Three signals representing $\mathrm{C}, \mathrm{O}$, and $\mathrm{Cl}$ for $\mathrm{PVC}$ were displayed (Figures 5(a) and 5(c)). Meanwhile, the fabricated bionanocomposite demonstrated the presence of significant signals for $\mathrm{C}, \mathrm{O}$, and $\mathrm{Ag}$ (Figures 5(b) and 5(d)). No other elemental impurity was observed. The study of the EDX spectra of PVC and the fabricated bionanocomposite confirmed the successful distribution of Moringa oleifera oil and AgNPs within the PVC polymer matrix.

3.3. Thermal Stability of Bionanocomposite Films. The thermal stability of the bionanocomposite films was based on the inherent features of samples as well as the interaction between the reacted molecules. The bond dissociation of the polymeric chain occurs when the thermal energy exceeded the bond dissociation energy [28]. The fabricated bionanocomposite films were subjected to thermogravimetric analysis to prove the interaction between the organic and inorganic nanomaterial surfaces. The stability of the formed Moringa oleifera oil/PVC-AgNP films using different wt $\%$ of PVC-AgNPs (5wt\%, $8 \mathrm{wt} \%$, and $10 \mathrm{wt} \%$ ) were investigated, and the obtained curves are presented in Figure 6. It was observed that the loss of weight was started above $120^{\circ} \mathrm{C}$, and the obtained values were 150 , 175 , and $248^{\circ} \mathrm{C}$ for the previously mentioned Moringa oleifera oil/PVC-AgNP films, respectively. The estimated amount of desorbed water was nearly $2.0 \%$. The major loss of weight occurred in between 150 and $250^{\circ} \mathrm{C}$ for the tested film, which is attributed to the organic phase desorption. Thus, the film displayed a greater thermal stability, up to $250^{\circ} \mathrm{C}$. It is worth mentioning that the addition of the high wt\% of PVC increased the residual weight due to the carbonaceous material possibly originating from the decomposition of the high molecular weight polymer.

3.4. Antimicrobial Activity. Moringa oleifera oil and the Moringa oleifera oil/PVC-AgNP bionanocomposite exhibited different sensitivity toward all the stains used (Figure 7). Collectively, all organisms were sensitive to 


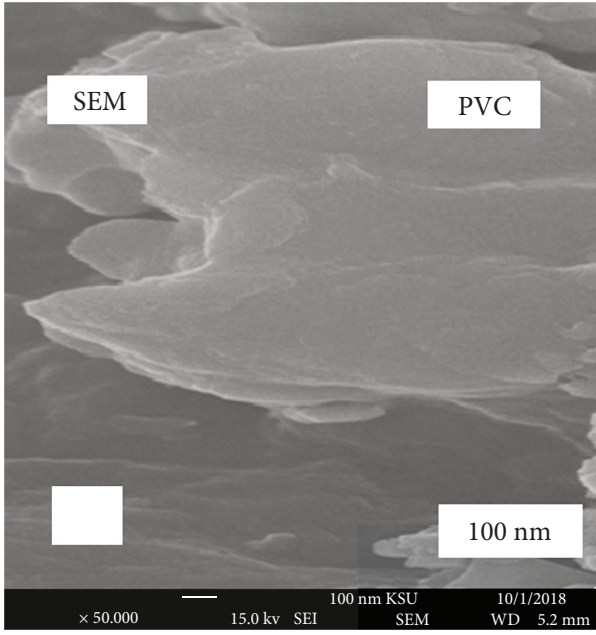

(a)

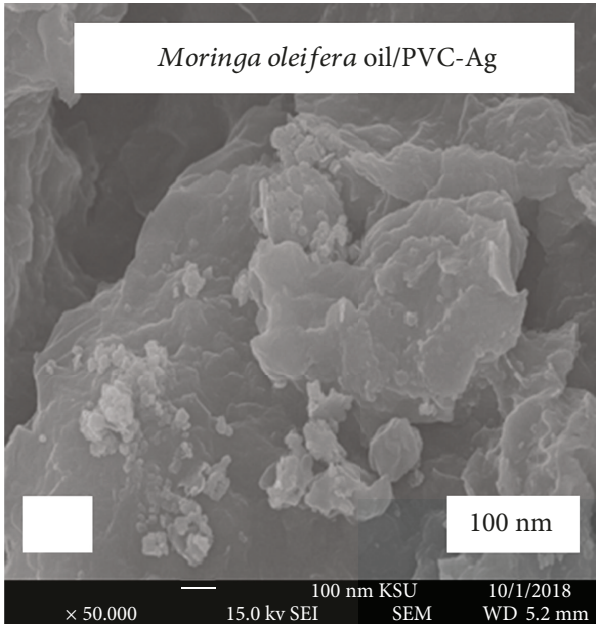

(c)

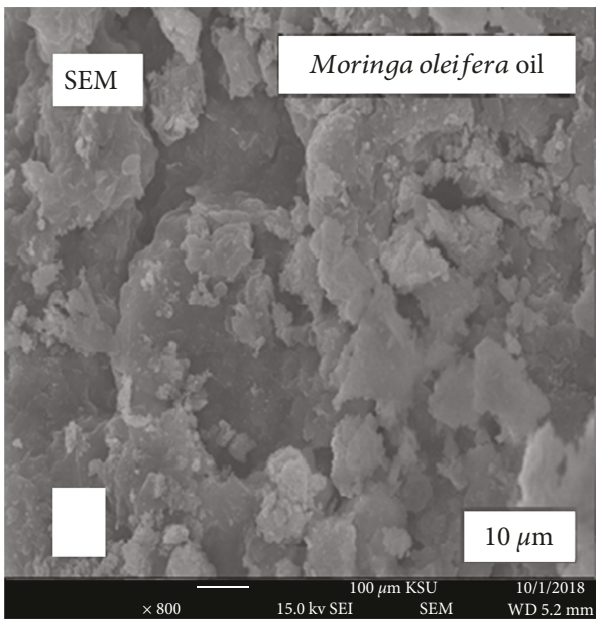

(e)

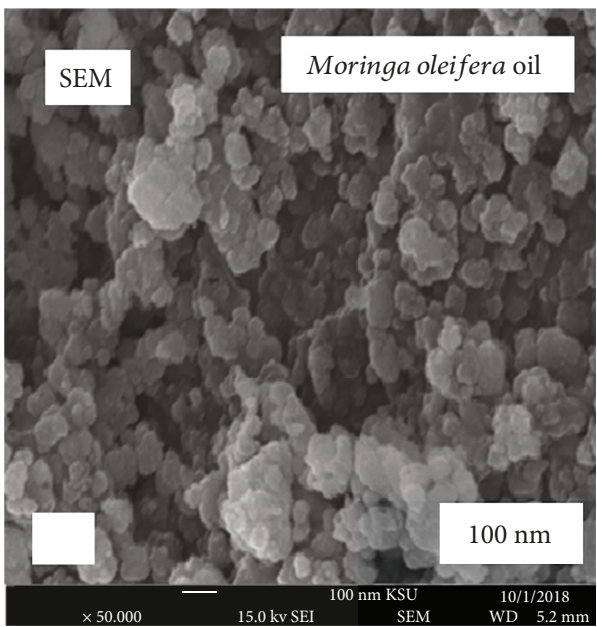

(b)

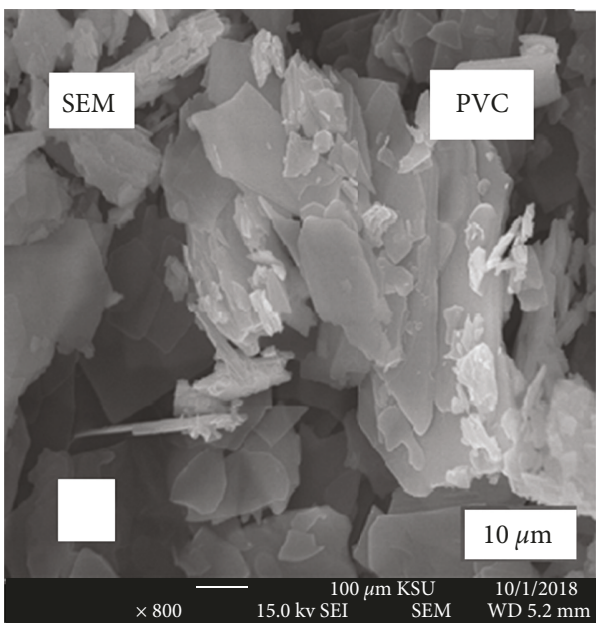

(d)

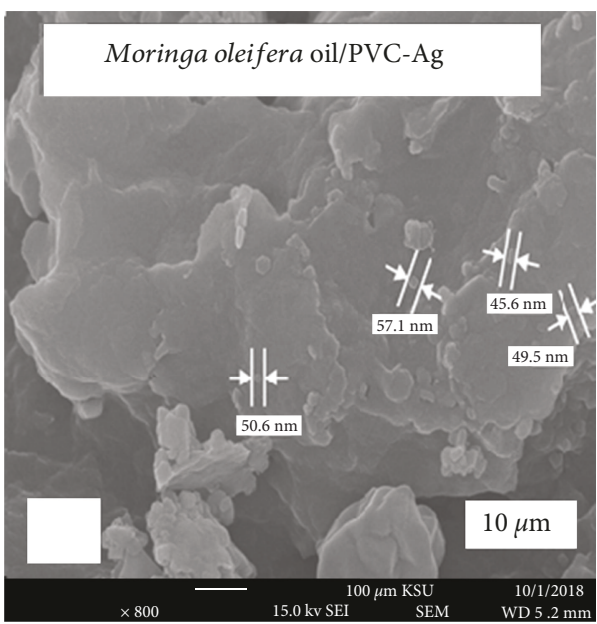

(f)

FIgUre 2: SEM images of ( $\mathrm{a}$ and d) plain PVC, ( $\mathrm{b}$ and e) Moringa oleifera oil, and (c and $\mathrm{f}$ ) Moringa oleifera oil/PVC-AgNPs at 50000x and 800x magnifications.

the Moringa oleifera oil as well as Moringa oleifera oil/PVC-AgNP bionanocomposite. The Moringa oleifera oil and bionanocomposite showed varying degrees of antibacte- rial activities against these selected pathogens. The results show that bionanocomposite has a greater antibacterial activity over the Moringa oleifera seed oil (Figure 8). 


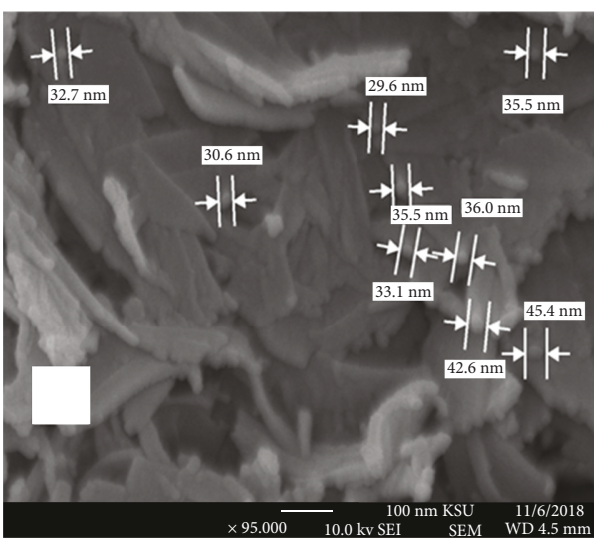

(a)

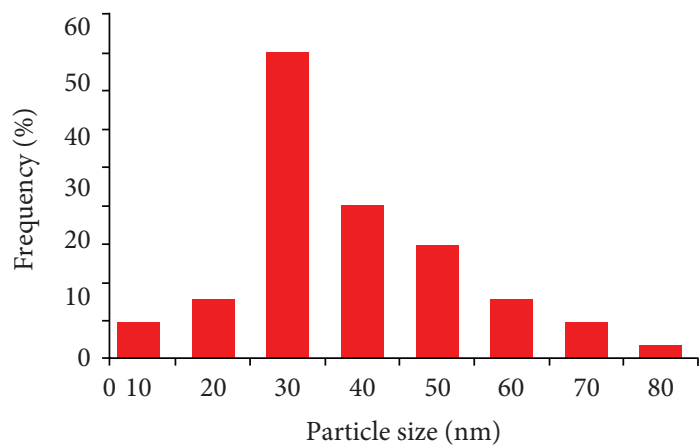

(c)

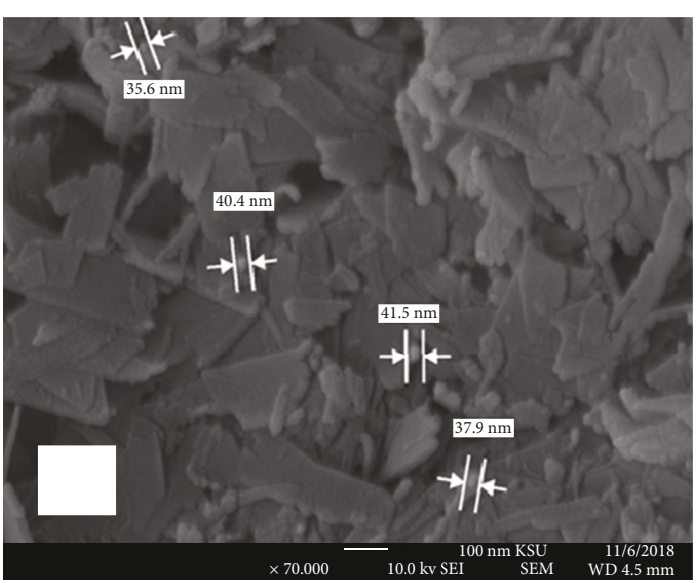

(b)

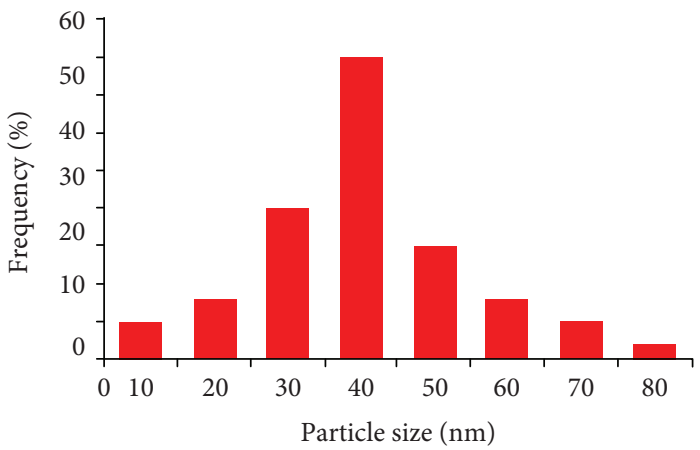

(d)

FIgURE 3: SEM images of (a) PVC containing $10 \mathrm{wt} \%$ of Moringa oleifera oil and (b) Moringa oleifera oil/PVC-AgNPs. The particle size distribution and diameter were determined for (a) and (b) as shown in (c) and (d), respectively.

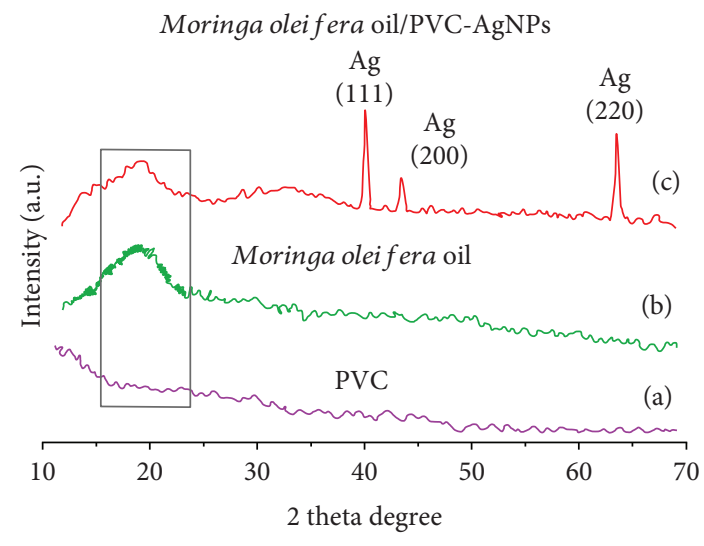

FIGURE 4: XRD pattern of (a) plain PVC, (b) Moringa oleifera oil, and (c) Moringa oleifera oil/PVC-AgNP bionanocomposite.

The MIC of Moringa oleifera oil and the Moringa oleifera oil/PVC-AgNP bionanocomposite were determined against seven strains of microorganisms, i.e., Staphylococcus aureus (gram positive), Escherichia coli, Klebsiella pneumoniae, Salmonella typhi, Pseudomonas aeruginosa, and Shigella flexneri (gram negative), and a fungus, Candida albicans. MIC is defined as the lowest concentration of both Moringa oleifera oil and the Moringa oleifera oil/PVC-AgNP bionanocomposite resulting in inoculum growth inhibition. Three concentrations were found to have mostly affected the growth of all strains. Absorbance in each well was measured at $590 \mathrm{~nm}$ compared with the negative control and recorded in Table 2. Also, the bionanocomposite had a broader spectrum of antibacterial potential than the Moringa seed oil against six isolates of bacteria, i.e., Staphylococcus aureus, Escherichia coli, Klebsiella pneumoniae, Salmonella typhi, Pseudomonas aeruginosa and Shigella flexneri $(8 \mathrm{~mm})$, at $50 \mathrm{mg} \mathrm{mL}^{-1}$ concentrations. It can also be deduced that the bionanocomposite had a higher antibacterial activity than the Moringa seed oil against all six isolates of bacteria with inhibition zones ranging between 10 and $16 \mathrm{~mm}$ at $50 \mathrm{mg} \mathrm{mL}^{-1}$ concentration. A minimum concentration $12.5 \%$ of the bionanocomposite was completely suitable to inhibit the growth of all cultivated strains. Also, it was observed that the Moringa oleifera oil/PVC-AgNP bionanocomposite demonstrated bactericidal and fungicidal activities with an MIC of $0.125 \mathrm{~g} \mathrm{~mL}^{-1}$ (Table 2).

\section{Conclusion}

The present study focused on the use of PVC as a supporting material for the fabrication of a polymeric Moringa oleifera oil bionanocomposite enriched with 


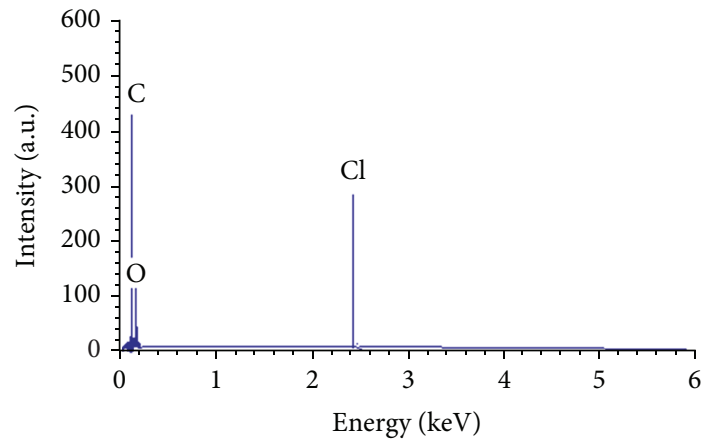

(a)

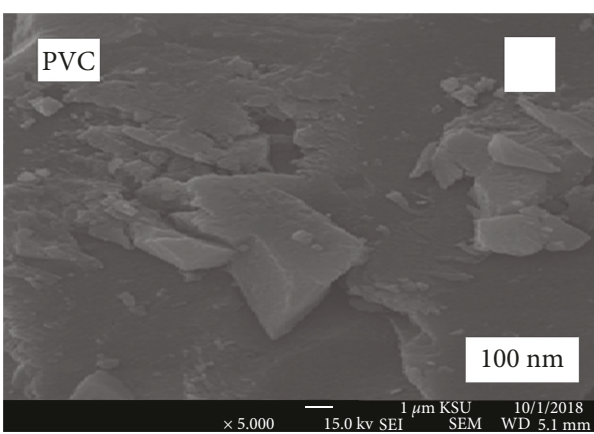

(c)

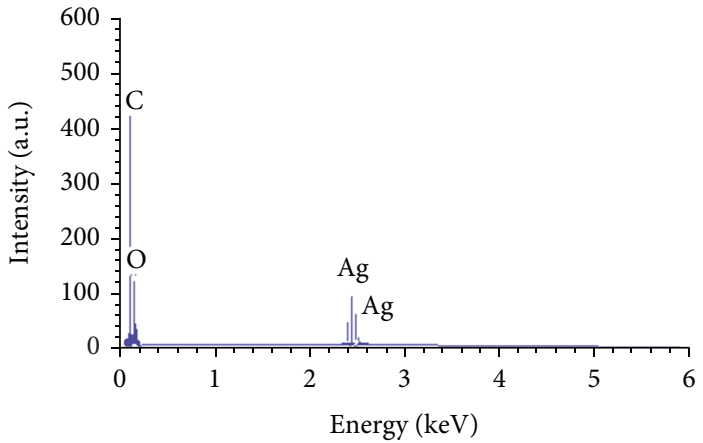

(b)

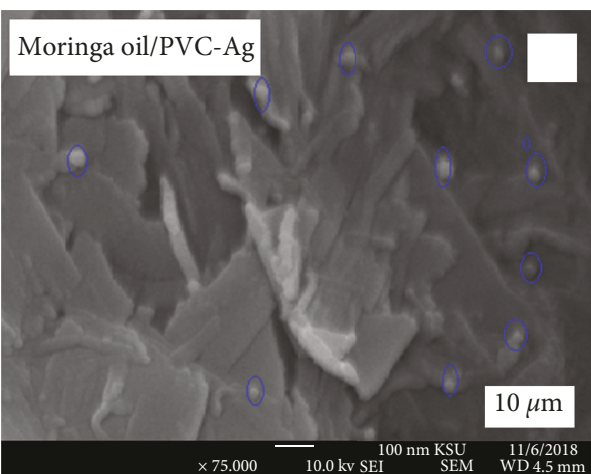

(d)

FIgURE 5: EDX spectra of (a) PVC and (b) Moringa oleifera oil/PVC-AgNPs. The image in (c) represents the SEM of PVC. The image in (d) represents the SEM of AgNPs in the Moringa oleifera oil/PVC-AgNP bionanocomposite.

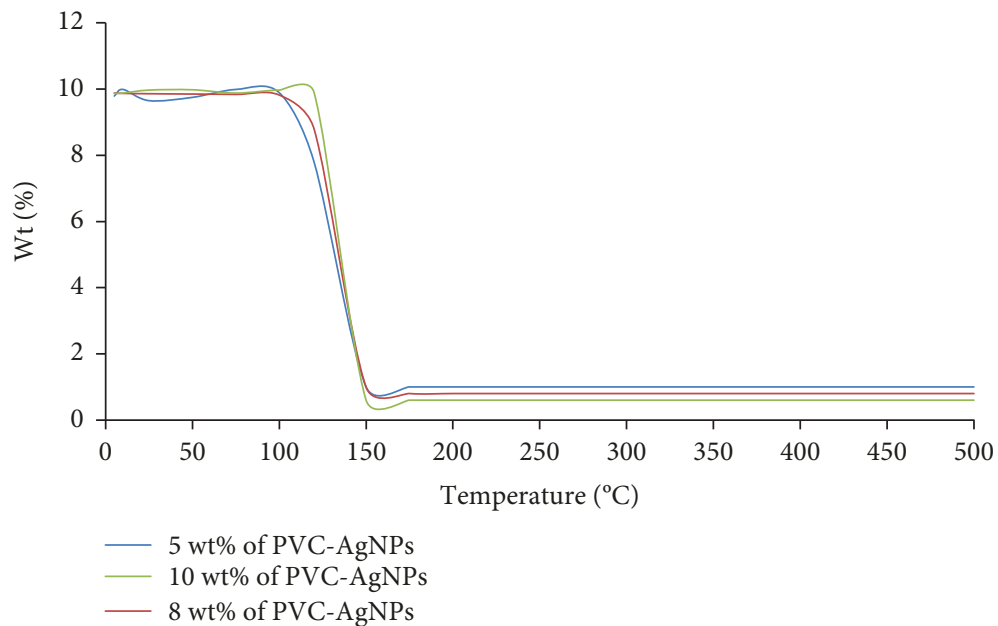

Figure 6: Thermogravimetric analysis of Moringa oleifera oil/PVC-AgNP bionanocomposite films containing different concentrations of $5 \mathrm{wt} \%-10 \mathrm{wt} \%$ of PVC-AgNPs.

$40 \mathrm{~nm}$ of silver nanoparticles (AgNPs). The isolated oil contained 14 antioxidant phenolic compounds representing $98.2 \%$ of the total oil composition. The characterization of the fabricated film has revealed an efficient dispersion of Moringa oleifera oil and AgNPs in the PVC matrix with a very high thermal stability up to $250^{\circ} \mathrm{C}$. The prepared bionanocomposite proved to have an efficient antimicro- bial activity on 7 pathogenic microorganisms with an MIC of $0.125 \mathrm{~g} \mathrm{~mL}^{-1}$. Nanoencapsulation can enhance products in different industries such as food products with extensive functionality. The benefits are enormous such as simplicity of handling, structural sustainability, superior stability, controlled moisture and $\mathrm{pH}$-triggered release, and boosted bioavailability and antimicrobial activity. Silver 


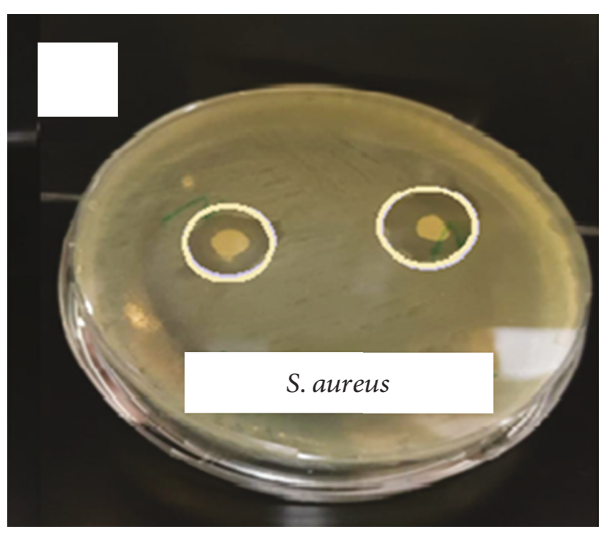

(a)

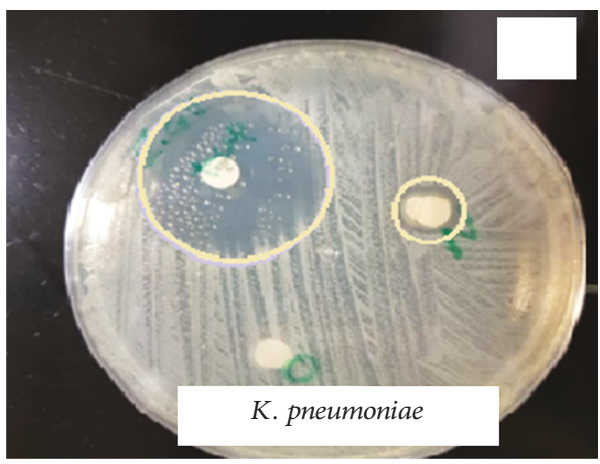

(c)

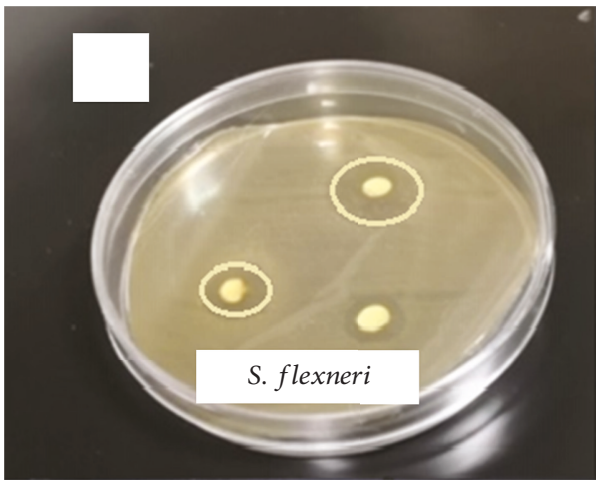

(e)

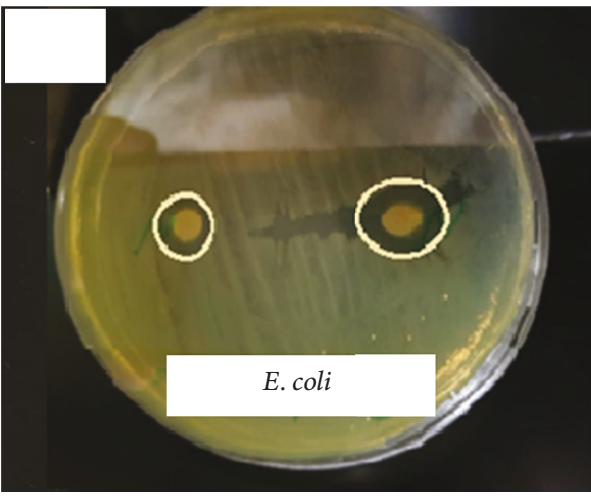

(b)

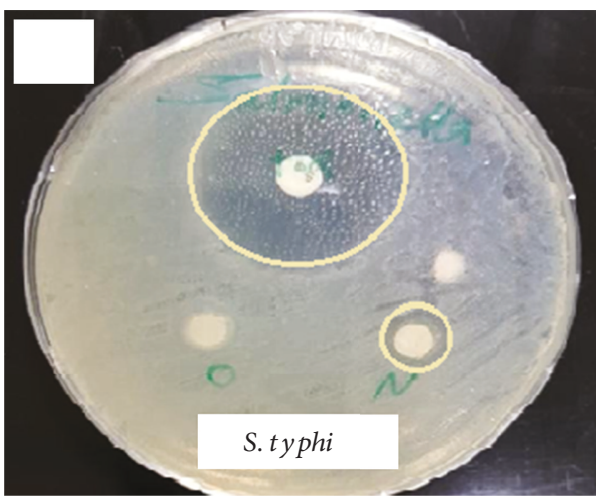

(d)

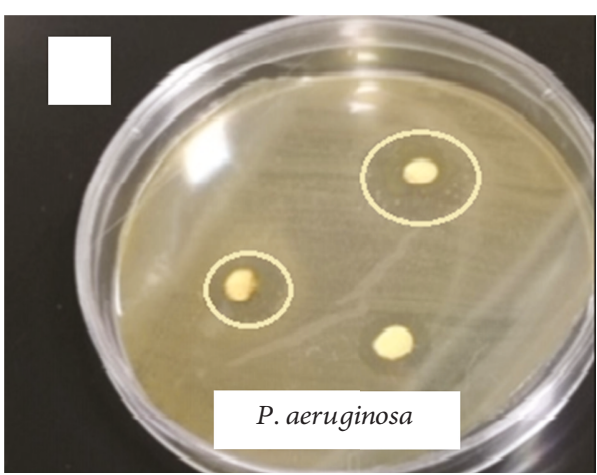

(f)

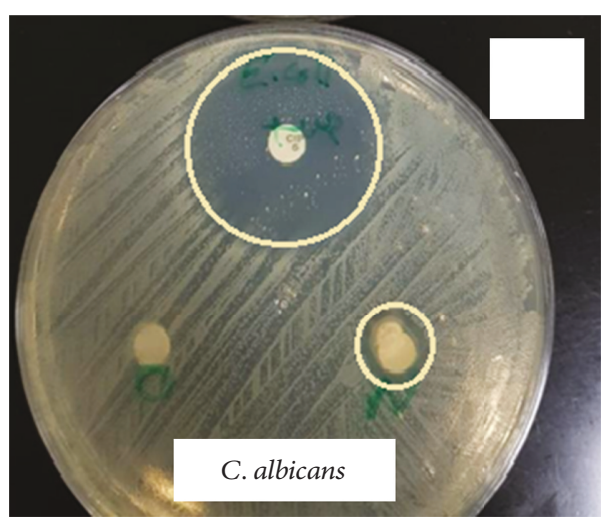

(g)

FIGURE 7: Screening of the Moringa oleifera oil/PVC-AgNP bionanocomposite for antibacterial and antifungal activities by disc diffusion assay. 


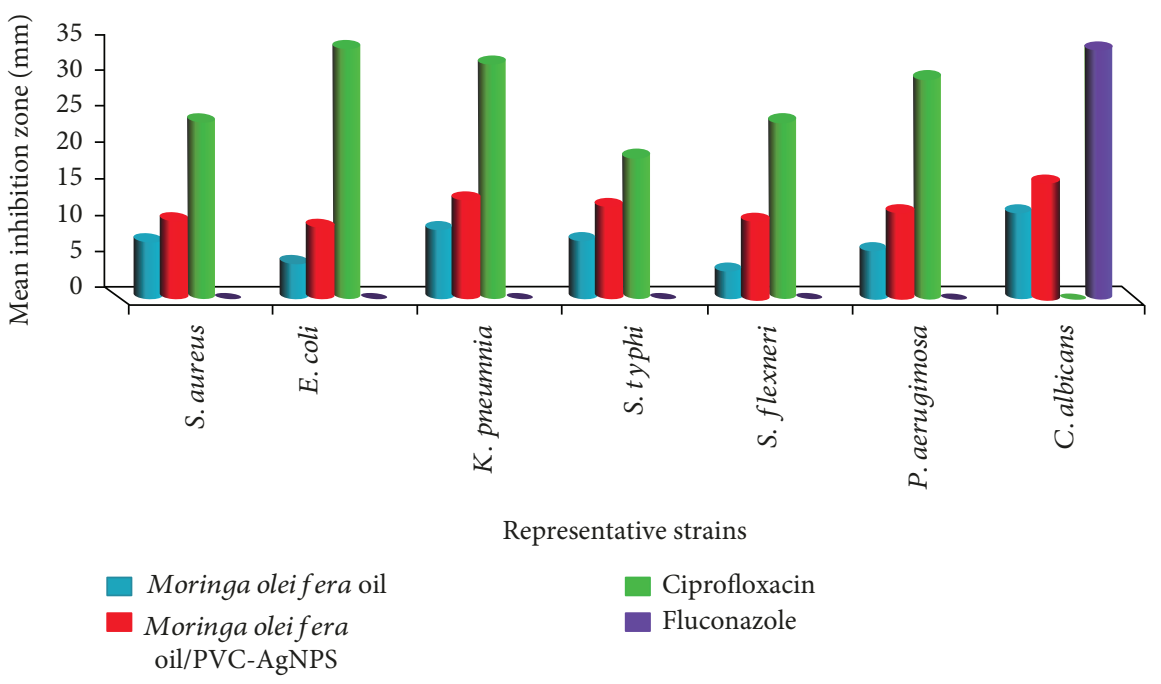

FIGURE 8: Comparison of the antibacterial activity of Moringa oleifera seed oil and Moringa oleifera oil/PVC-AgNP bionanocomposites against representative strains.

TABle 2: Antimicrobial activity of $M$. oleifera seed oil and M. oleifera oil/PVC-AgNPs.

\begin{tabular}{|c|c|c|c|c|c|c|c|}
\hline \multirow{2}{*}{ Sample } & \multirow{2}{*}{$\begin{array}{c}\text { Gram (positive) } \\
\text { S. aureus }\end{array}$} & \multicolumn{5}{|c|}{ Gram (negative) } & \multirow{2}{*}{$\begin{array}{l}\text { Fungus } \\
\text { C. albicans }\end{array}$} \\
\hline & & E. coli & K. pneumoniae & S. typhi & S. flexneri & P. aeruginosa & \\
\hline Moringa oleifera oil & 8 & 5 & 10 & 8 & 4 & 7 & 12 \\
\hline \multicolumn{8}{|c|}{ Moringa oleifera oil/PVC-AgNPs } \\
\hline $5 \mathrm{wt} \%$ & $11 \pm 0.6$ & $10 \pm 1.2$ & $14 \pm 0.8$ & $13 \pm 0.6$ & $11 \pm 0.7$ & $12 \pm 1.1$ & $16 \pm 1.4$ \\
\hline $8 w t \%$ & $13 \pm 1.5$ & $12 \pm 0.8$ & $16 \pm 1.4$ & $14 \pm 0.4$ & $13 \pm 1.6$ & $16 \pm 1.7$ & $20 \pm 0.6$ \\
\hline $10 \mathrm{wt} \%$ & $18 \pm 0.7$ & $14 \pm 1.1$ & $20 \pm 1.5$ & $16 \pm 0.6$ & $18 \pm 0.8$ & $22 \pm 0.8$ & $23 \pm 0.4$ \\
\hline Ciprofloxacin $5 \mu \mathrm{g} / \mathrm{disc}$ & 25 & 35 & 33 & 20 & 25 & 31 & - \\
\hline Fluconazole $5 \mu \mathrm{g} /$ disc & - & - & - & - & - & - & 35 \\
\hline $\mathrm{MIC}\left(\mathrm{g} \mathrm{mL}^{-1}\right)$ & 0.125 & 0.125 & 0.125 & 0.125 & 0.125 & 0.125 & 0.125 \\
\hline
\end{tabular}

metal nanoparticles breached into the film have the constraining effect of various respiratory process enzymes and impede the infiltration of protons and phosphate through the cell membrane, ultimately decreasing the ATP production levels well contained in the cell. Thus, mixing bionanocomposites such as the Moringa oleifera oil/PVC film enriched with AgNPs within the food packaging products could restrain the growth of pathogenic microorganisms and increase food quality and shelf life. Although nanoencapsulation could be efficient in controlling pathogenic microorganisms, there still are several points that need to be investigated related to any side effects and regulations of using nanoparticles in controlling microorganisms [29].

\section{Data Availability}

The data used to support the findings of this study are included within the article.

\section{Conflicts of Interest}

The authors declare no conflict of interest.

\section{Acknowledgments}

This research project was supported by a grant from the "Research Center of the Center for Female Scientific and Medical Colleges," Deanship of Scientific Research, King Saud University.

\section{References}

[1] A. Palizban, B. Bakhshaei, and G. Asghari, "Quantitative analysis of the nutritional components in leaves and seeds of the Persian Moringa peregrina (Forssk.) Fiori," Pharmaceutical Research, vol. 7, no. 3, pp. 242-248, 2015.

[2] F. Anwar, M. Ashraf, and M. I. Bhanger, "Interprovenance variation in the composition of Moringa oleifera oil seeds from Pakistan," Journal of the American Oil Chemists' Society, vol. 82, no. 1, pp. 45-51, 2005. 
[3] S. Zhao and D. Zhang, "A parametric study of supercritical carbon dioxide extraction of oil from Moringa oleifera seeds using a response surface methodology," Separation and Purification Technology, vol. 113, pp. 9-17, 2013.

[4] F. Anwar, S. Latif, M. Ashraf, and A. H. Gilani, "Moringa oleifera: a food plant with multiple medicinal uses," Phytotherapy Research, vol. 21, no. 1, pp. 17-25, 2007.

[5] C. Ramachandran, K. V. Peter, and P. K. Gopalakrishnan, "Drumstick (Moringa oleifera): a multipurpose Indian vegetable," Economic Botany, vol. 34, no. 3, pp. 276-283, 1980.

[6] M. Mahmood, T. Mugal, and I. U. Haq, "Moringa oleifera: a natural gift-a review," Journal of Pharmaceutical Sciences and Research, vol. 2, pp. 775-781, 2010.

[7] J. O. Palafox, A. Navarrete, J. C. Sacramento-Rivero, C. RubioAtoche, P. A. Escoffie, and J. A. Rocha-Uribe, "Extraction and characterization of oil Moringa oleifera using supercritical $\mathrm{CO}_{2}$ and traditional solvents," American Journal of Analytical Chemistry, vol. 03, no. 12, pp. 946-949, 2012.

[8] K. Ruttarattanamongko and A. Petrasch, "Antimicrobial activities of Moringa oleifera seed and seed oil residue and oxidative stability of its cold pressed oil compared with extra virgin olive oil," Songklanakarin Journal of Science and Technology, vol. 37, pp. 587-594, 2015.

[9] N. A. Aviara, W. B. Musa, O. K. Owolarafe, B. S. Ogunsina, and F. A. Oluwole, "Effect of processing conditions on oil point pressure of Moringa oleifera seed," Journal of Food Science and Technology, vol. 52, no. 7, pp. 4499-4506, 2015.

[10] J. D. Dziezak, "Microencapsulation and encapsulated ingredients," Food Technology, vol. 42, pp. 136-148, 1988.

[11] S. Li, M. M. Lin, M. S. Toprak, D. K. Kim, and M. Muhammed, "Nanocomposites of polymer and inorganic nanoparticles for optical and magnetic applications," Nanotechnology Reviews, vol. 1, no. 1, p. 5214, 2010.

[12] C. M. Finzi-Quintao, A. C. Bernardes-Silva, T. M. S. Melo, L. E. S. Moreira, T. D. Silva, and K. M. Novack, "Moringa oleifera oil and polymer in mixtures with commercial polymers-comparing study," International Journal of Development Research, vol. 8, pp. 22111-22117, 2018.

[13] C. M. Finzi-Quintão, K. M. Novack, A. C. Bernardes-Silva, T. D. Silva, L. E. S. Moreira, and L. E. M. Braga, "Biodegradation of Moringa oleifera's polymer blends," Environmental Technology, vol. 40, no. 4, pp. 508-517, 2017.

[14] A. A. Abd-Rabou, A Zoheir KhM, M. S. Kishta, A. B. Shalby, and M. I. Ezzo, "Nano-micelle of Moringa oleifera seed oil triggers mitochondrial cancer cell apoptosis," Asian Pacific Journal of Cancer Prevention, vol. 17, no. 11, pp. 4929-4933, 2016.

[15] M. W. Allsopp and G. Vianello, "Poly(vinyl chloride)," in Ullmann's Encyclopedia of Industrial Chemistry, Wiley-VCH, Weinheim, 2012.

[16] S. Lakshmi and A. Jayakrishnan, "Properties and performance of sulfide-substituted plasticized poly (vinyl chloride) as a biomaterial," Biomaterials, vol. 65B, no. 1, pp. 204-210, 2003.

[17] P. Norouzi, H. Rashed, A. Alipour, F. Faridbod, S. J. Shahtaheri, and M. R. Ganjali, "PVC membrane sensor and wire coated electrode for determination of flurazepam," International Journal of Electrochemical Science, vol. 6, pp. 2312-2322, 2011.
[18] J. H. Han, J. D. Taylor, D. S. Kim et al., "Glucose biosensor with a hydrophilic polyurethane (HPU) blended with polyvinyl alcohol/vinyl butyral copolymer (PVAB) outer membrane," Sensors and Actuators B: Chemical, vol. 123, no. 1, pp. 384-390, 2007.

[19] Health Care Without Harm, "Alternatives to polyvinyl chloride (PVC) and di(2-ethylhexyl) phthalate (DEHP) medical devices," 2006, November 2007, http://www.noharm.org/ details.cfm?type $=$ document $\&$ id $=591$.

[20] H. Xu, D. Dinsdale, B. Nemery, and P. H. Hoet, "Role of residual additives in the cytotoxicity and cytokine release caused by polyvinyl chloride particles in pulmonary cell cultures," Toxicological Sciences, vol. 72, no. 1, pp. 92-102, 2003.

[21] R. P. Adams, Identification of Essential Oil Components by GC-MS, Allured Publishing Corp, Carol Stream, IL, USA, 1995.

[22] F. W. McLafferty and D. B. Stauffer, The Wiley NBS Registry of Mass Spectral Data, Wiley International Publication, 1989.

[23] J. Sfeir, C. Lefrançois, D. Baudoux, S. Derbré, and P. Licznar, "In vitro antibacterial activity of essential oils against Streptococcus pyogenes," Evidence-based complementary and alternative medicine, vol. 2013, Article ID 269161, 9 pages, 2013.

[24] K. A. Hammer, C. F. Carson, and T. V. Riley, "In-vitro activity of essential oils, in particular Melaleuca alternifolia (tea tree) oil and tea tree oil products, against Candida spp," The Journal of Antimicrobial Chemotherapy, vol. 42, no. 5, pp. 591-595, 1998.

[25] A. N. Devkatte, G. B. Zore, and S. M. Karuppayil, "Potential of plant oils as inhibitors of Candida albicans growth," FEMS Yeast Research, vol. 5, no. 9, pp. 867-873, 2005.

[26] F. Ammari, M. Dardouri, M. Kahlaoui, and F. Meganem, "Structure and electrical study of new chemically modified poly(vinyl chloride)," International Journal of Polymer Science, vol. 2015, Article ID 280325, 5 pages, 2015.

[27] K. Shameli, M. Ahmad, P. Shabanzadeh et al., "Green biosynthesis of silver nanoparticles using Curcuma longa tuber powder," International Journal of Nanomedicine, vol. 7, pp. 5603-5610, 2012.

[28] B. I. Dogaru, M. C. Popescu, and B. C. Simionescu, “Thermal stability of bio-nanocomposite films based on poly (vinyl alcohol)/starch/cellulose nano-crystals," Revue Roumaine de Chimie, vol. 62, pp. 599-604, 2017.

[29] D. Sharma and D. Dhanjal, "Bio-nanotechnology for active food packaging," Journal of Applied Pharmaceutical Science, vol. 6, pp. 220-226, 2016. 


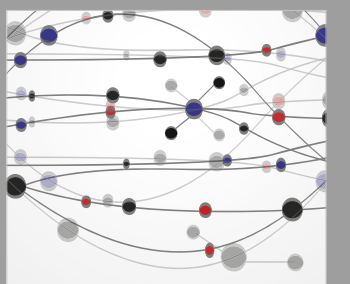

The Scientific World Journal
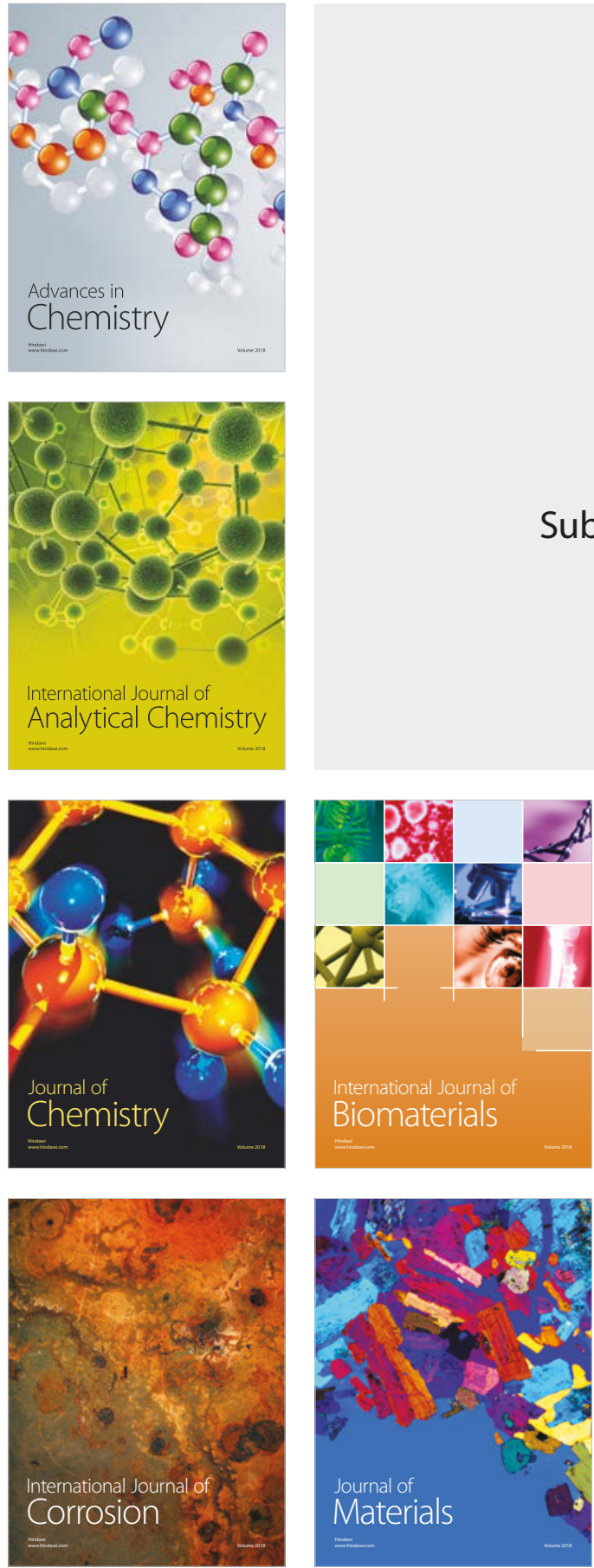

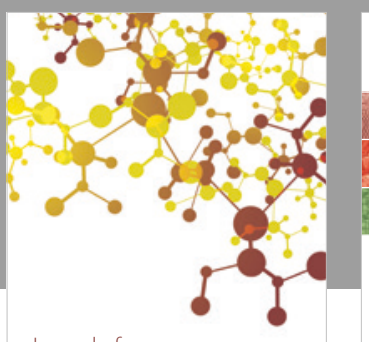

Journal of

Applied Chemistry
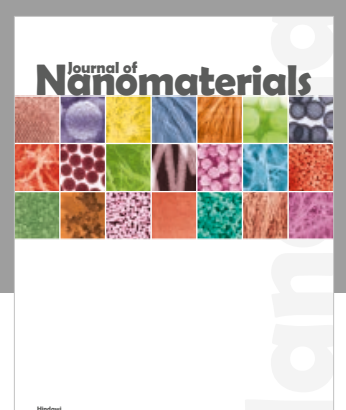

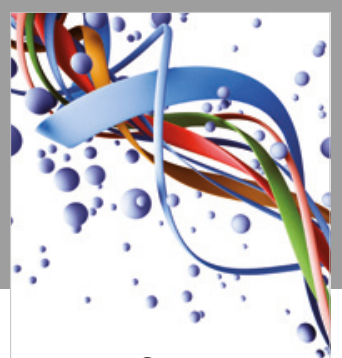

Scientifica

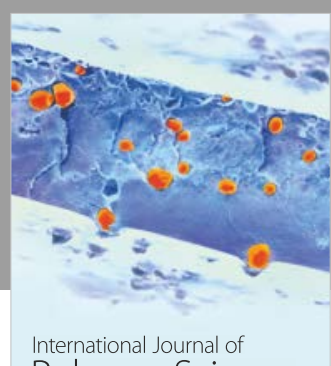

Polymer Science

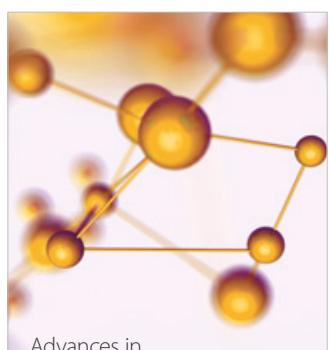

Physical Chemistry
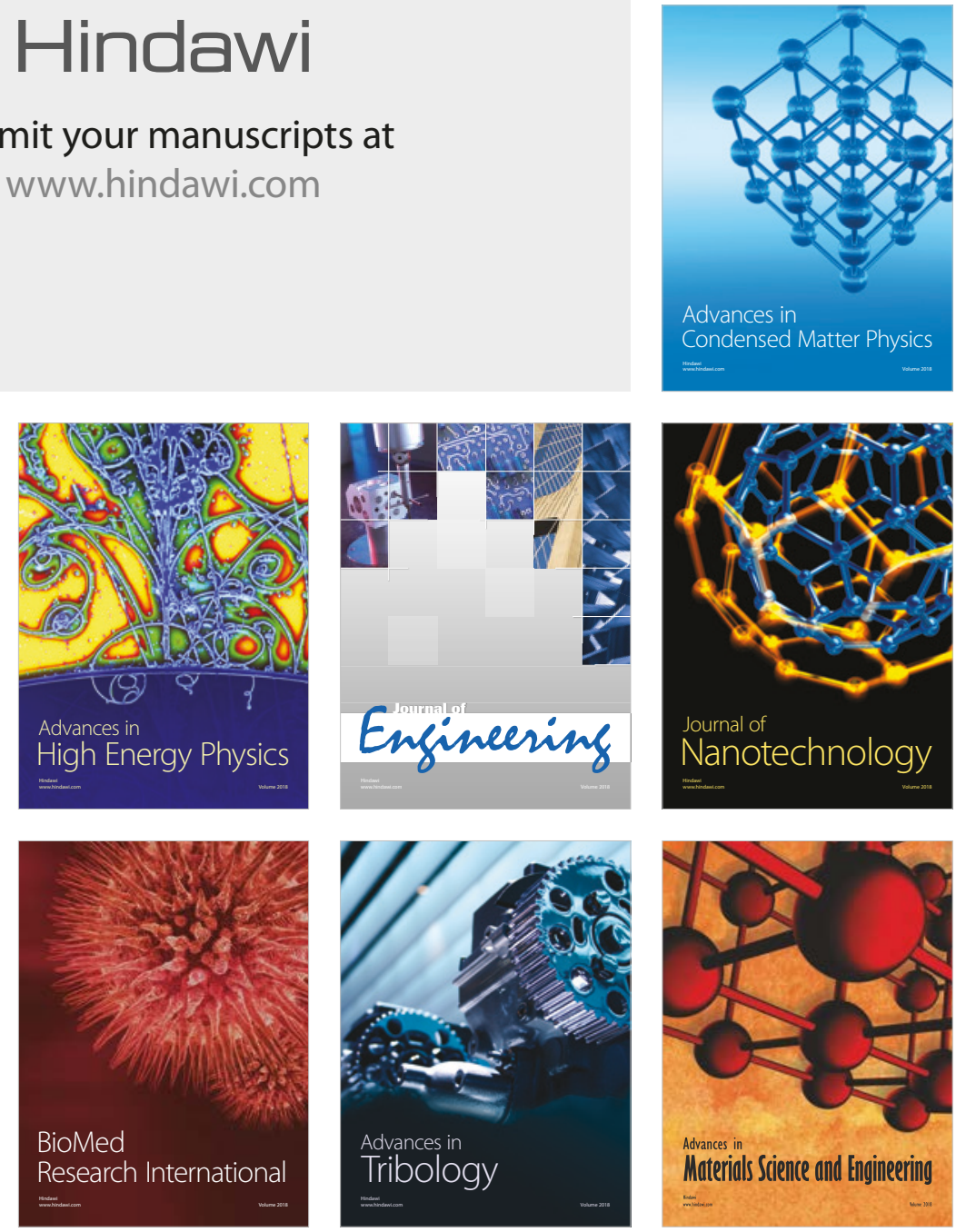